\title{
Low sun exposure habits is associated with a dose-dependent increased risk of hypertension: a report from the large MISS cohort
}

\author{
Pelle G. Lindqvist ${ }^{1,2}\left(\right.$ D $\cdot$ M. Landin-Olsson ${ }^{3} \cdot$ H. Olsson ${ }^{4}$
}

Received: 7 October 2020 / Accepted: 27 January 2021 / Published online: 18 February 2021

(c) The Author(s) 2021

\begin{abstract}
In prospective observational cohort studies, increasing sun exposure habits have been associated with reduced risk of cardiovascular mortality. Our aim was to assess possible observational mechanisms for this phenomenon. A written questionnaire was answered by 23,593 women in the year 2000 regarding risk factors for melanoma, including factors of possible interest for hypertension, such as detailed sun exposure habits, hypertension, marital status, education, smoking, alcohol consumption, BMI, exercise, and chronic high stress. Hypertension was measured by the proxy "use of hypertension medication" 2005-2007, and high stress by "need of anti-depressive medication". Sun exposure habits was assessed by the number of 'yes' to the following questions; Do you sunbath during summer?, During winter vacation?, Do you travel south to sunbath?, Or do you use sun bed? Women answering 'yes' on one or two questions had moderate and those answering 'yes' on three or four as having greatest sun exposure. The main outcome was the risk of hypertension by sun exposure habits adjusted for confounding. As compared to those women with the greatest sun exposure, women with low and moderate sun exposure were at $41 \%$ and $15 \%$ higher odds of hypertension (OR 1.41, 95\% CI 1.3-1.6, $p<0.001$ and OR 1.15, 95\% CI 1.1-1.2, $p<0.001$ ), respectively. There was a strong age-related increased risk of hypertension. Other risk factors for hypertension were lack of exercise (OR 1.36), a non-fair phenotype (OR 1.08), chronic high stress level (OR 1.8), and lack of university education (OR 1.3). We conclude that in our observational design sun exposure was associated with a dose-dependent reduced risk of hypertension, which might partly explain the fewer deaths of cardiovascular disease with increasing sun exposure.
\end{abstract}

Keywords Sun exposure $\cdot$ Cardiovascular disease $\cdot$ Hypertension $\cdot$ Risk factors $\cdot$ UV radiation

\section{Introduction}

An inverse association has been shown between cardiovascular disease (CVD) and vitamin D levels [1-3]. Chowedhury and coworkers estimated that $9.4 \%$ of all deaths in Europe and $12.8 \%$ in the US may be associated with vitamin D levels $<75 \mathrm{nmol} / \mathrm{L}$ [4]. However, prospective trials of vitamin $\mathrm{D}$ supplementation have not been able to show

Pelle G. Lindqvist

Pelle.lindqvist@ki.se

1 Department of Clinical Science and Education, Karolinska Institutet, Huddinge, Sweden

2 Department of Obstetrics and Gynecology, Sodersjukhuset, Sjukhusbacken 10, Plan 9, 11861 Stockholm, Sweden

3 Department of Endocrinology, Clinical Sciences, Lund University Hospital, Lund, Sweden

4 Departments of Oncology and Cancer Epidemiology, Lund University Hospital, Lund, Sweden benefit in terms of CVD [5]. However, the authors comment on several limitations of the studies such as no prespecified endpoint, underpowered and low doses [5]. In line with the latter, Afzal and coworkers used Mendelian randomization analysis to demonstrate that genotypes associated with low $25(\mathrm{OH}) \mathrm{D}$ levels were linked to a $14 \%$ increase in all-cause mortality for each $8 \mathrm{ng} / \mathrm{mL}$ lower vitamin D level, but not for CVD mortality [6]. Thus, there is a possibility that low vitamin $\mathrm{D}$ levels related to CVD might be a marker of something else.

It has been reported that at high latitudes women with active sun exposure habits have been associated with greater life expectancy, compared to those with inactive sun habits [7-9]. Compared to those with moderate and greatest sun exposure habits, women $>55$ years of age with low sun exposure habits were at 1.5 -fold and 2.3 -fold, increased likelihood of death from CVD and one month shorter life expectancy per year $[9,10]$. It was estimated that low sun exposure was a risk factor in the same magnitude as smoking 
for all-cause death [9]. Thus, in terms of CVD mortality, low vitamin $\mathrm{D}$ levels may be a marker of low sun exposure. Those with active sun exposure habits have sufficient vitamin D levels all year around, while those with inactive sun exposure are at low levels most of the year [11].

Feelisch and coworkers reported that UV radiation caused arterial vasodilatation resulting in a decrease in blood pressure [12]. Thus, UV radiation has been shown to lower transient blood pressure. It was hypothesized that CVD benefits of sunlight may be mediated by mechanisms other than vitamin $\mathrm{D}[12,13]$. However, it is still not known if individual sun exposure habits are related to persistent blood pressure or hypertension.

The aim of this study was to assess whether low sun exposure habits are associated with persistent high blood pressure as measured by the use of antihypertensive medication among those in the large prospective MISS cohort.

\section{Materials and methods}

\subsection{Study design}

The Melanoma in Southern Sweden (MISS) study was initiated in 1990. Our subjects consisted of approximately 1000 Sweden-born women of every age from 25 to $64(n=39,973)$ who had no history of malignancy. The subjects were selected from the general population registry of the South Swedish Health Care Region by random computerized selection and represented $20 \%$ of the female population of South Sweden in the selected age groups. The women were invited to complete a standardized written questionnaire concerning risk factors for malignant melanoma. The initial inquiry was carried out from 1990 to 1992, and 29,518 women were subsequently enrolled in the study (response rate 74\%).

A written follow-up inquiry was then conducted between 2000 and 2002 . The questionnaire answered by 23,593 , was a detailed inquiry into several factors of potential interest for blood pressure, such as sun exposure habits, marital status, educational level, smoking habits, alcohol consumption, use of combined oral contraceptives (COC), BMI, physical exercise, fair phenotype, and chronic high stress level.

We used background data from interview year 2000. We define hypertension as those who have been prescribed antihypertensive medication by their physician. In 2005-01-01 to 2007 all prescriptions filled in Sweden were recorded in the National Prescription Register. Those women with a prescription from Pharmaceutical Specialities Sweden (FASS) group; $\mathrm{C} 02 *$ (anti hypertension), $\mathrm{C} 07 *$ (beta blocker), $\mathrm{C} 08^{*}$ (calcium antagonists), or $\mathrm{C} 09^{*}$ (affecting renin-angiotensin system) were classified as having hypertension. Women who responded to the questionnaire during year 2000 and who had a prescription registered from 2005 to 2007 were included $(n=21,260)$.

\subsection{Sun exposure assessment}

Four questions were asked regarding sun exposure: (1) how often do you sunbathe during the summertime? (never, $1-14$ times, $15-30$ times, $>30$ times); (2) Do you sunbathe during the winter, such as on holiday to the mountains? (no; $1-3$ days, $4-10$ days; $>10$ days); (3) Do you use tanning beds? (never; $1-3$ times/year; $4-10$ times/year; $>10$ times/ year); and (4) Do you go abroad on holiday to swim and sunbathe? (never; once every 1-2 years; once/year; two or more times/year). The four questions were dichotomized into yes/no in the analysis (i.e. "no/never" or "sometimes"). As a measure of total sun exposure, sun exposure habits were categorized into three groups: zero "yes" responses (low sun exposure); "yes" response to one or two questions (moderate exposure); and "yes" response to three or four questions (greatest exposure).

\subsection{Variable definitions}

Smoking habits were recorded as smoker or nonsmoker. Weight and height were recorded and BMI was calculated in $\mathrm{kg} / \mathrm{m}^{2}$. BMI was classified into four groups: $<25$ (reference), 25 to $<30$ (overweight), $\geq 30 \mathrm{~kg} / \mathrm{m}^{2}$ (obese) and BMI missing. The level of regular exercise was categorized into three groups: none; walking at least once per week; or strenuous exercise (reference) such as cycling, swimming, gymnastics, or dancing $\geq$ once/week [14]. Women reporting having red hair or freckles were categorized as fair; other women were listed as non-fair. Women who had used COC for more than 5 years were classified as prior COC users. We classified those women on anti-depressant therapy as suffering from high chronic stress. Anti-depressive medication (i.e. having a FASS group N06A* prescription) is used for several condition such as; depression, burn out, and sleeping difficulties (when a high stress level is considered the cause). We believe that "chronic high stress level" is the shared characteristics for women on anti-depressive medication and use this classification.

The study was approved by the Ethics Committee of Lund University (LU 632-03).

\subsection{Statistical analysis}

Descriptive statistical analysis of the cohort who answered the year 2000 questionnaire was performed using crosstabulation with a $95 \%$ confidence interval (CI) for those women with and without active sun exposure habits (Table 1). In Table 2 we present crude and adjusted logistic regression models for risk of hypertension. Hypertension 
Table 1 Background variables and hypertension by sun exposure habits

\begin{tabular}{|c|c|c|c|c|c|c|}
\hline & \multicolumn{6}{|c|}{ Sun exposure habits } \\
\hline & \multicolumn{2}{|l|}{ Low } & \multicolumn{2}{|c|}{ Moderate $^{\mathrm{a}}$} & \multicolumn{2}{|c|}{ Greatest $^{\mathrm{b}}$} \\
\hline & 1904 & $\%$ & 12,938 & $\%$ & 6418 & $\%$ \\
\hline \multicolumn{7}{|l|}{ Age group (years) } \\
\hline $35-44$ & 171 & 9.0 & 2630 & 20.3 & 1880 & 29.3 \\
\hline $45-54$ & 200 & 10.5 & 2956 & 22.8 & 2048 & 31.9 \\
\hline $55-64$ & 465 & 24.4 & 3447 & 26.6 & 1665 & 25.9 \\
\hline $65-74$ & 1068 & 56.1 & 3905 & 30.2 & 825 & 12.9 \\
\hline \multicolumn{7}{|l|}{ Exercise } \\
\hline None & 238 & 12.5 & 1138 & 8.8 & 398 & 6.2 \\
\hline Moderate & 787 & 41.3 & 5940 & 45.9 & 2802 & 43.7 \\
\hline Strenuous & 335 & 17.6 & 3734 & 28.9 & 2709 & 42.2 \\
\hline$?$ & 544 & 28.6 & 2126 & 16.4 & 509 & 7.9 \\
\hline \multicolumn{7}{|l|}{ Alcohol intake } \\
\hline$<5$ g/day & 857 & 45.0 & 2693 & 20.8 & 695 & 10.8 \\
\hline $5-<15 \mathrm{~g} /$ day & 726 & 38.1 & 6495 & 50.2 & 2874 & 44.8 \\
\hline$>15 \mathrm{~g} /$ day & 246 & 12.9 & 3663 & 28.3 & 2805 & 43.7 \\
\hline$?$ & 75 & 3.9 & 87 & 0.7 & 44 & 0.7 \\
\hline Fair phenotype & 781 & 41.0 & 5431 & 42.0 & 2929 & 45.6 \\
\hline \multicolumn{7}{|l|}{ BMI } \\
\hline$<25$ & 668 & 35.1 & 6530 & 50.5 & 4010 & 62.5 \\
\hline $25-30$ & 537 & 28.2 & 3848 & 29.7 & 1677 & 26.1 \\
\hline$>30$ & 337 & 17.7 & 1505 & 11.6 & 415 & 6.5 \\
\hline$?$ & 362 & 19.0 & 1055 & 8.2 & 316 & 4.9 \\
\hline Smoker & 786 & 41.3 & 6823 & 52.7 & 3892 & 60.6 \\
\hline$?$ & 70 & 3.7 & 150 & 1.2 & 65 & 1.0 \\
\hline Prior $\mathrm{COC}>5$ years & 306 & 16.1 & 4002 & 30.9 & 2771 & 43.2 \\
\hline University school & 463 & 24.3 & 4209 & 32.5 & 2629 & 41.0 \\
\hline Married & 1220 & 64.1 & 9514 & 73.5 & 4927 & 76.8 \\
\hline Chronic stress & 333 & 17.5 & 2144 & 16.6 & 1000 & 15.6 \\
\hline
\end{tabular}

Hypertension (HT) as measured by "use of antiHT" medication 2005 to 2007

Chronic stress as measured by use of anti-depressant medication

prior COC Combined oral contraceptives at least 5 years, ? Missing value

${ }^{a}$ Moderate sun exposure: answer yes to one or two of the following questions; Do you sunbath during summer?, during winter vacation?, do you travel south to sunbath?, or do you use sun bed?

${ }^{b}$ Greatest sun exposure: answering yes to three or four of the above questions was used as a dependent variable; other selected variables were introduced as independent variables. Some independent variables were introduced because of their known relationships, such as age, smoking, and exercise level. Others were included if $p$ values were less than 0.2 (alcohol consumption, university education, marital status, fair phenotype, prior use of COC, and chronic stress). Since BMI has been suggested as in the causal pathway of sun exposure, we predetermined to consider it only as a stratified variable [15]. Missing values were included in the adjusted analysis as a dummy variable. Thus, all cases were included in Tables 1 and 2, and no imputation was used. IBM SPSS 23 (Statistical Package for the Social Sciences, SPSS Inc., Chicago IL, USA) software was used for descriptive analysis and logistic regression analysis; $p$ values $<0.05$ were considered statistically significant.

\section{Results}

\subsection{Background characteristics}

In Table 1 we present the background characteristics of women with low, moderate and greatest sun exposure habits, i.e., having answered yes on zero, one or two, or three or four of the four sun exposure questions, respectively. Sun exposure habits differed in relation to most selected background variables. 
Table 2 Risk of Hypertension by sun exposure habits

\begin{tabular}{|c|c|c|c|c|c|c|c|c|c|c|c|c|}
\hline & \multicolumn{4}{|c|}{ Hypertension (HT) } & \multirow{2}{*}{\multicolumn{2}{|c|}{$\frac{\text { Crude analysis }}{\text { OR for HT }}$}} & \multirow{2}{*}{\multicolumn{2}{|c|}{$\frac{\text { Adj analysis } 1^{\mathrm{a}}}{\text { OR for HT }}$}} & \multirow{2}{*}{\multicolumn{2}{|c|}{$\frac{\text { str analysis } 2^{\mathrm{b}}}{\mathrm{BMI}<25}$}} & \multirow{2}{*}{\multicolumn{2}{|c|}{$\frac{\text { str analysis } 3^{\mathrm{c}}}{\mathrm{BMI} \geq 25}$}} \\
\hline & \multirow{2}{*}{\multicolumn{2}{|c|}{$\begin{array}{l}\text { No } \\
n=14,747\end{array}$}} & \multirow{2}{*}{\multicolumn{2}{|c|}{$\begin{array}{l}\text { Yes } \quad \% \\
n=6513\end{array}$}} & & & & & & & & \\
\hline & & & & & OR & $95 \% \mathrm{CI}$ & OR & $95 \% \mathrm{CI}$ & OR & $95 \% \mathrm{CI}$ & OR & $95 \% \mathrm{CI}$ \\
\hline \multicolumn{13}{|l|}{ Sun exposure ${ }^{a}$} \\
\hline Low exposure & 1007 & 6.8 & 897 & 13.8 & 3.0 & $2.7-3.4$ & 1.41 & $1.3-1.6$ & 1.4 & $1.1-1.7$ & 1.5 & $1.1-2.0$ \\
\hline Moderate & 8773 & 59.5 & 4165 & 63.9 & 1.6 & $1.5-1.7$ & 1.15 & $1.1-1.2$ & 1.2 & $1.1-1.4$ & 1.2 & $0.9-1.5$ \\
\hline Greatest & 4967 & 33.7 & 1451 & 22.3 & 1.0 & Ref & 1.0 & Ref & 1.0 & Ref & 1.0 & Ref \\
\hline \multicolumn{13}{|c|}{ Age group year $2000^{c}$ (years) } \\
\hline $35-44$ & 4195 & 28.4 & 486 & 7.5 & 1.0 & Ref & 1.0 & Ref & 1.0 & Ref & 1.0 & Ref \\
\hline $45-54$ & 4093 & 27.8 & 1111 & 17.1 & 2.3 & $2.1-2.6$ & 2.5 & $2.2-2.9$ & 2.7 & $2.1-3.5$ & 2.5 & $1.8-3.5$ \\
\hline $55-64$ & 3625 & 24.6 & 1952 & 30.0 & 4.6 & $4.2-5.2$ & 4.6 & $4.1-5.2$ & 4.7 & $3.6-6.0$ & 4.3 & $3.1-5.9$ \\
\hline $65-74$ & 2834 & 19.2 & 2964 & 45.5 & 9.0 & $8.1-10.0$ & 8.2 & $7.2-9.4$ & 9.3 & $7.3-11.8$ & 6.1 & $4.4-8.4$ \\
\hline \multicolumn{13}{|l|}{ Exercise } \\
\hline None & 1251 & 8.5 & 523 & 10.4 & 1.4 & $1.3-1.6$ & 1.36 & $1.2-1.5$ & 1.4 & $1.1-1.7$ & 1.0 & $0.8-1.4$ \\
\hline Moderate & 6581 & 44.6 & 2948 & 58.8 & 1.5 & $1.4-1.6$ & 1.31 & $1.2-1.4$ & 1.3 & $1.1-1.5$ & 0.9 & $0.7-1.2$ \\
\hline Strenuous & 5242 & 35.5 & 1536 & 30.7 & 1.0 & Ref & 1.0 & Ref & 1.0 & Ref & 1.0 & Ref \\
\hline$?$ & 1673 & 11.3 & 1506 & 23.1 & 3.1 & $2.8-3.4$ & 1.35 & $1.2-1.5$ & 1.39 & $1.1-1.5$ & 1.14 & $0.9-1.5$ \\
\hline \multicolumn{13}{|l|}{ Alcohol intake } \\
\hline$<5$ g/day & 2514 & 17.0 & 1731 & 26.6 & 1.6 & $1.4-1.7$ & 1.19 & $1.1-1.3$ & 1.1 & $0.9-1.2$ & 1.1 & $0.9-1.4$ \\
\hline $5-<15$ g/day & 7000 & 47.5 & 3095 & 47.5 & 1.0 & Ref & 1.0 & Ref & 1.0 & Ref & 1.0 & Ref \\
\hline$>15 \mathrm{~g} /$ day & 5109 & 34.6 & 2518 & 38.7 & 0.7 & $0.7-0.8$ & 0.9 & $0.8-1.0$ & 1.1 & $0.9-1.2$ & 1.1 & $1.0-1.2$ \\
\hline$?$ & 124 & 0.8 & 82 & 1.3 & 1.5 & $1.1-2.0$ & 1.14 & $0.8-1.6$ & 1.38 & $0.8-2.4$ & 0.83 & $0.3-2.5$ \\
\hline Non-fair phenotype & 8124 & 55.1 & 3995 & 61.3 & 1.3 & $1.2-1.4$ & 1.08 & $1.01-1.15$ & 1.1 & $1.0-1.2$ & 1.1 & $1.0-1.4$ \\
\hline High stress & 2243 & 13.2 & 1234 & 18.9 & 1.3 & $1.2-1.4$ & 1.80 & $1.4-2.3$ & 2.5 & $1.6-3.8$ & 1.2 & $0.7-2.2$ \\
\hline University & 5495 & 37.3 & 1806 & 27.7 & 0.6 & $0.6-0.7$ & 0.79 & $0.7-0.8$ & 0.9 & $0.8-1.0$ & 0.9 & $0.7-1.0$ \\
\hline \multicolumn{13}{|l|}{$\mathrm{BMI}^{\mathrm{b}}$} \\
\hline$<25$ & 8607 & 58.4 & 2601 & 39.9 & 1.0 & Ref & & & Included & & & \\
\hline $25-30$ & 3920 & 26.6 & 2142 & 32.9 & 1.8 & $1.7-1.9$ & & & & & Included & \\
\hline$>30$ & 1218 & 8.3 & 1039 & 16.0 & 2.8 & $2.6-3.1$ & & & & & Included & \\
\hline$?$ & 1002 & 6.8 & 731 & 11.2 & 2.41 & $2.2-2.7$ & & & & & & \\
\hline Smoker & 8313 & 56.4 & 3188 & 48.9 & 0.7 & $0.7-0.8$ & & & & & & \\
\hline Married & 11,018 & 74.7 & 4643 & 71.3 & 0.8 & $0.8-0.9$ & & & & & & \\
\hline Prior $\mathrm{COC}>5$ years & 5548 & 37.6 & 1531 & 23.5 & 0.5 & $0.5-0.5$ & & & & & & \\
\hline
\end{tabular}

Since BMI has been suggested to be in the causal pathway between sun exposure and CVD it was predetermined to only be presented in stratified analysis

${ }^{a}$ Adjusted for all shown variables shown in column, Str stratified, ? Denotes missing data

${ }^{\mathrm{b}}$ Adjusted as above among non-overweight

${ }^{\mathrm{c}}$ Adjusted for same variables as model 1 only among those with BMI $>25$

\subsection{Outcome}

In Table 2 we present the selected variables in relation to hypertension, together with crude ORs and three adjusted models. The main outcome is presented in adjusted model 1. Women with low and moderate sun exposure habits were at $41 \%$ and $15 \%$ higher odds of hypertension, respectively, as compared to those with greatest sun exposure habits (model 1, Fig. 1). As expected there is a strong relationship between increasing age and the odds of hypertension. Also, women with chronic high stress were at almost double risk of hypertension (OR 1.8, 95\% CI 1.4-2.3). Women who did not exercise were at a $36 \%$ increased association to hypertension (OR 1.36, 95\% CI 1.2-1.5) (Fig. 1). In our modeling smoking, marital status and prior use of COC were not significantly related to hypertension. We tested for interactions and found an interaction between age group and high stress; this interaction was included in models 1 to 3 . When high stress was introduced, OR for hypertension increased from OR $1.4,95 \%$ CI $1.3-1.6$ to OR $1.8,95 \%$ CI $1.8-2.8$. The OR of overweight (1.5, 95\% CI 1.4-1.6) and obesity (2.4, 95\% CI 2.1-2.6) for hypertension are not included in model 

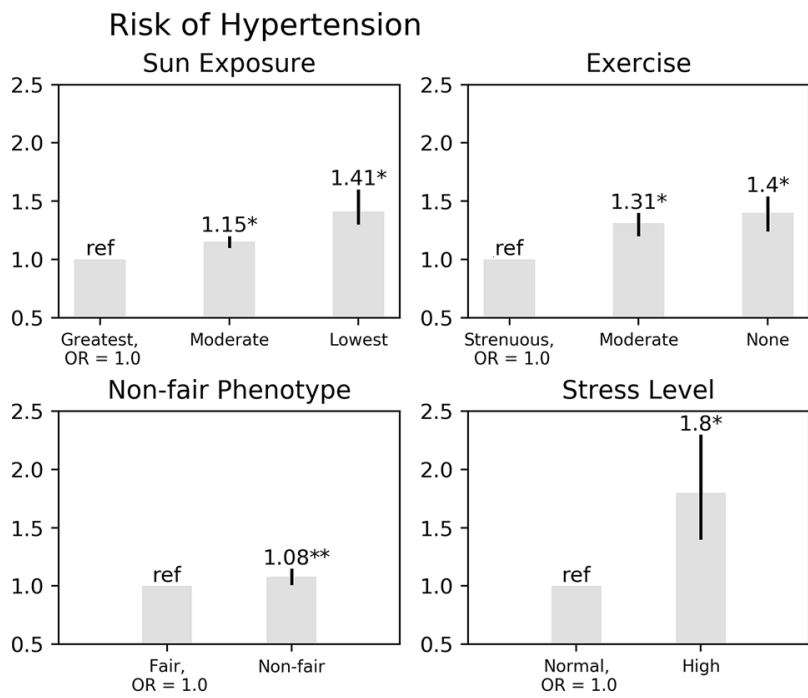

Fig. 1 Risk of hypertension. As compared to greatest sun exposure, moderate and low sun exposure were related to $15 \%$ and $41 \%$ increased odds of hypertension. As compared to strenuous exercise moderate and no exercise were related to $31 \%$ and $40 \%$ increased odds of hypertension. Women with Non-fair and those with a high stress level were at $8 \%$ and $80 \%$ increased odds of hypertension. $*$ Denotes significance of difference $p<0.001,{ }^{* *} p=0.02$

1 , but data are given stratified in model 2 and model 3 . The OR of women with $\mathrm{BMI}<$ and $\geq 25$ were similar as the OR in model 1 , but with a wider CI.

In Supplementary Table 1 we show the same data as Table 2, adjusted analysis 1 also including BMI in model 1 , in model 2 including all women who answered the questionnaire. Finally in model 3, we include the same data as Table 2, model 2, but excluding participants with missing variables.

\section{Discussion and conclusion}

In this study we find an inverse dose-dependent association between sun exposure habits and hypertension, adjusted for possible covariates. We sought to assess if the lower CVD mortality associated with active sun exposure habits might be mediated through a persistent reduction in blood pressure, which was found. Although our findings are of an observational nature, they lend some support to the hypothesis that low vitamin D levels in relation to CVD might be a marker of low sun exposure, and not the mediator of hypertension. Thus, this could explain why vitamin D supplementation does not seem to affect the risk of CVD. In addition, lack of exercise, increasing stress, and having a non-fair phenotype were related to a significantly increased OR for hypertension.
In agreement with our findings, a Chinese study reported that women who sunbathed $30 \mathrm{~min}$ per day had a $40 \%$ lower risk of hypertension [16]. In a Saudi Arabian study, the risk of hypertension decreased from 28.1 to $11.1 \%$, blood pressure decreased from a mean of 118.3/76.0-112.6/73.9 and the mean BMI dropped, with recommendation of increased dietary vitamins and 5-30 min of sun exposure twice a week for 1 year. The sun exposure was recommended before 10 o'clock or after 14, i.e., when the UV index was not high (UV index $>6$ ) [17]. Two studies report an inverse relationship between ambient UV radiation and systolic blood pressure $[18,19]$. The US study found a $59 \%$ increased risk of stroke in areas below the median of ambient UV radiation, as compared to above [18]. Blood pressure was reported to be independent of vitamin $\mathrm{D}[18,20]$. A recent study comprising dialysis patients in the US shows that higher incident UV radiation, to be associated with lower blood pressure [21]. There are several interventional studies assessing the effect of UVA and/or UVB light on the effect on transient blood pressure. There seems to be a transient effect resulting from UV radiation, but studies to date have been small and have had divergent results [12, 22-25].

\subsection{Possible mechanisms that may explain the relationship between sun exposure and the lower risk of CVD mortality}

Liu and co-workers reported that large stores of nitrogen oxides (NO) mobilized into the systemic circulation in response to UV radiation lowered blood pressure, a finding that was reportedly independent of temperature and vitamin D [12]. Since hypertension is a major risk factor for stroke and myocardial infarction, a plausible reason for the sun exposure associated reduced CVD mortality might be a mediating vasodilator effect of $\mathrm{NO}$, which in turn reduces blood pressure. Lack of exercise is a known risk factor for both hypertension and CVD [26]. In addition, both exercise and sun exposure increase sweating, which contain sodium chloride. A low salt status is related to lower blood pressure, and a lower risk of hypertension [27]. It is not possible to differentiate active sun exposure habits from a healthy lifestyle with more activity and less overweight. However, smoking and alcohol consumption was higher. Hypertension is a major driver for the global burden of disease, especially for myocardial infarction and stroke. If sun exposure does affect long-term blood pressure, it may be a modifiable risk factor $[28,29]$. In our observational design, sun exposure is associated with lower incidence of several of the major common diseases such as; type 2 diabetes mellitus, thromboembolism, hypertension, CVD, and non-CVD/non-cancer mortality $[9,14,30]$.

Sun exposure also have an anxiolytic effect by endorphin release [31]. Chronic stress has been shown to cause 
endothelial dysfunction, hypertension, and atherosclerosis [32-34]. A randomized trial comprising vitamin D-deficient depressed individuals showed a reduction from 24 to 13 on the Beck Depression Inventory by prescribing safe sun exposure and activating exercise for 12 weeks [35]. Thus, approximately half of those in the study participants were cured at time point 2 , while the control group remained at a mean score of 23. Whole body UV exposure for dermal conditions improved the Montgomery Åsberg Depression Rating Scale (MADRS) significantly after 6 weeks as compared to control group receiving placebo light [36]. Lack of endorphin may cause the activation of sympathetic nerves resulting in increased stress. It has recently been shown that melanocytic stem cells were prematurely depleted in response to high stress causing decoloration of the hair [37]. In accordance with above, our data show that women with a high chronic stress level were at a doubled risk of hypertension.

Blacks have a higher prevalence of hypertension at 55 years of age as compare to whites [38]. We find non-fair Caucasian women to be at an $8 \%$ increased risk of hypertension compared to fair (Table 2). Although we compared different shades of white, the finding of an inverse association between fair phenotype and the risk of hypertension is in agreement with the reported survival advantage of fair skin in a low UV milieu, including a 59\% increased risk of death due to skin cancer [39]. Thus, assuming causality, the increased risk of death due to skin cancer might be interpreted as the "price" for a survival advantage in a low UV region.

It is not always possible to differentiate between the effects of cold and low UVR, but cold has been reported to upregulate central angiotensin receptors [40]. In order to increase body temperature in cold weather, the sympathetic nervous system and hypothalamic-pituitary-adrenal axis may be activated. Activation of the renin-angiotensin-aldosterone system will cause sodium and water retention [40]. A Japanese study reported that low solar radiation was associated with a substantial attributable risk for outside-hospital cardiac arrest [41]. Similarly, an increased risk of acute coronary events, stroke, and venous thromboembolism has been reported in winter [30, 42, 43]. Thus, the winter peak of CVD events may at least partially be explained by higher blood pressure due to a combination of cold and low UV exposure [44]. Preeclampsia is characterized by hypertension and proteinuria. The prevalence of eclampsia is almost doubled during the winter season in Sweden [45].

\subsection{Strengths and limitations}

It is a strength that our large cohort was drawn randomly from the Swedish population register for 1990. A drawback is that we do not know if all women with hypertension were diagnosed and treated with anti-hypertension medication or how many who had hypertension at inception. However, sun exposure habits tend to be quite constant [46]. In addition, some women will be prescribed a b-blocker for indications other than hypertension. However, we believe that our data will be valid on a group level. All findings are of observational type and may not be causal. We have relied on a single occasion assessment of sun exposure, which might cause bias. However, such a bias usually tends to underestimate differences [47]. We included only women receiving a prescription during 2005-2007. Thus, severely ill women who were in hospital or geriatric departments, or who died before 2005 were not included. Also, those who were most healthy and not taking prescription medicine were not included. Since we used different inclusion criteria with almost identical ORs (supplementary Table 1), we believe the results of Table 2 model 1 give the most accurate results.

We conclude that increased sun exposure seems to be associated to a dose-dependent reduced risk of hypertension, which at least in part may mediate the lower CVD mortality observed among those with greater sun exposure habits. This does not rule out other possible mechanisms, such as reduced stress or altered glucose metabolism by sun exposure.

Supplementary Information The online version contains supplementary material available at https://doi.org/10.1007/s43630-021-00017-x.

Acknowledgements This study was supported by funds from Vetenskapsrådet S113106103, the Swedish Cancer Society, and the Swedish Medical Research Council. It has also received funding from Lund University Hospital, Region Skåne, the Gustav V Jubilee Fund, the Gunnar Nilsson Foundation, the Kamprad Foundation, and the European Research Council Advanced Grant ERC-2011-294576. The funders of the study had no part in the writing, analysis, interpretation, or decision to submit the paper. We acknowledge Elliot Epstein for expert Phyton programming of the figure.

Author contributions HO was the initiator of the MISS cohort. PL and HO contributed with the study design. PL performed data analysis with input from all three authors and wrote the initial report. All authors have participated in the literature search, data interpretation, and writing of the final paper. All authors have approved of the final version of this paper.

Funding Open access funding provided by Karolinska Institute.

\section{Compliance with ethical standards}

Conflict of interest There are no conflicts of interest.

Informed consent Written informed consent was gathered from all participants.

Open Access This article is licensed under a Creative Commons Attribution 4.0 International License, which permits use, sharing, adaptation, distribution and reproduction in any medium or format, as long as you give appropriate credit to the original author(s) and the source, provide a link to the Creative Commons licence, and indicate if changes 
were made. The images or other third party material in this article are included in the article's Creative Commons licence, unless indicated otherwise in a credit line to the material. If material is not included in the article's Creative Commons licence and your intended use is not permitted by statutory regulation or exceeds the permitted use, you will need to obtain permission directly from the copyright holder. To view a copy of this licence, visit http://creativecommons.org/licenses/by/4.0/.

\section{References}

1. Giovannucci, E., Liu, Y., Hollis, B. W., \& Rimm, E. B. (2008). 25-hydroxyvitamin $\mathrm{D}$ and risk of myocardial infarction in men: A prospective study. Archives of Internal Medicine, 168(11), 1174-1180.

2. Pekkanen, M. P., Ukkola, O., Hedberg, P., Piira, O. P., Lepojarvi, S., Lumme, J., et al. (2015). Serum 25-hydroxyvitamin D is associated with major cardiovascular risk factors and cardiac structure and function in patients with coronary artery disease. Nutrition, Metabolism and Cardiovascular Diseases, 25(5), 471-478.

3. Kheiri, B., Abdalla, A., Osman, M., Ahmed, S., Hassan, M., \& Bachuwa, G. (2018). Correction to: Vitamin D deficiency and risk of cardiovascular diseases: A narrative review. Clinical Hypertension, 24, 19.

4. Chowdhury, R., Kunutsor, S., Vitezova, A., Oliver-Williams, C., Chowdhury, S., Kiefte-de-Jong, J. C., et al. (2014). Vitamin D and risk of cause specific death: Systematic review and meta-analysis of observational cohort and randomised intervention studies. $B M J$, 348, g1903.

5. Barbarawi, M., Kheiri, B., Zayed, Y., Barbarawi, O., Dhillon, H., Swaid, B., et al. (2019). Vitamin D supplementation and cardiovascular disease risks in more than 83000 individuals in 21 randomized clinical trials: A meta-analysis. JAMA Cardiology, 4(8), $765-776$

6. Afzal, S., Brondum-Jacobsen, P., Bojesen, S. E., \& Nordestgaard, B. G. (2014). Genetically low vitamin D concentrations and increased mortality: Mendelian randomisation analysis in three large cohorts. BMJ, 349, g6330.

7. Yang, L., Lof, M., Veierod, M. B., Sandin, S., Adami, H. O., \& Weiderpass, E. (2011). Ultraviolet exposure and mortality among women in Sweden. Cancer Epidemiology, Biomarkers and Prevention, 20(4), 683-690.

8. Lindqvist, P. G., Epstein, E., Landin-Olsson, M., Ingvar, C., Nielsen, K., Stenbeck, M., \& Olsson, H. (2014). Avoidance of sun exposure is a risk factor for all-cause mortality: Results from the Melanoma in Southern Sweden cohort. Journal of Internal Medicine, 276(1), 77-86.

9. Lindqvist, P. G., Epstein, E., Nielsen, K., Landin-Olsson, M., Ingvar, C., \& Olsson, H. (2016). Avoidance of sun exposure as a risk factor for major causes of death: A competing risk analysis of the Melanoma in Southern Sweden cohort. Journal of Internal Medicine, 280, 375-387.

10. Lindqvist, P. G., Epstein, E., Landin-Olsson, M., Åkerlund, M., \& Olsson, H. (2020). Women with fair phenotypes seem to confer a survival advantage in a low UV milieu. A nested matched case control study. PLOS ONE, 15(1), e0228582.

11. Brot, C., Vestergaard, P., Kolthoff, N., Gram, J., Hermann, A. P., \& Sorensen, O. H. (2001). Vitamin D status and its adequacy in healthy Danish perimenopausal women: Relationships to dietary intake, sun exposure and serum parathyroid hormone. British Journal of Nutrition, 86(Suppl 1), S97-103.

12. Liu, D., Fernandez, B. O., Hamilton, A., Lang, N. N., Gallagher, J. M., Newby, D. E., et al. (2014). UVA irradiation of human skin vasodilates arterial vasculature and lowers blood pressure independently of nitric oxide synthase. The Journal of Investigative Dermatology, 134(7), 1839-1846.

13. Feelisch, M., Kolb-Bachofen, V., Liu, D., Lundberg, J. O., Revelo, L. P., Suschek, C. V., \& Weller, R. B. (2010). Is sunlight good for our heart? European Heart Journal, 31(9), 1041-1045.

14. Lindqvist, P. G., Olsson, H., \& Landin-Olsson, M. (2010). Are active sun exposure habits related to lowering risk of type 2 diabetes mellitus in women, a prospective cohort study? Diabetes Research and Clinical Practice, 90(1), 109-114.

15. Vimaleswaran, K. S., Berry, D. J., Lu, C., Tikkanen, E., Pilz, S., Hiraki, L. T., et al. (2013). Causal relationship between obesity and vitamin D status: bi-directional Mendelian randomization analysis of multiple cohorts. PLoS Medicine, 10(2), e1001383.

16. Ke, L., Ho, J., Feng, J., Mpofu, E., Dibley, M. J., Feng, X., et al. (2014). Modifiable risk factors including sunlight exposure and fish consumption are associated with risk of hypertension in a large representative population from Macau. Journal of Steroid Biochemistry and Molecular Biology, 144 Pt A, 152-155.

17. Al-Daghri, N. M., Alkharfy, K. M., Al-Saleh, Y., Al-Attas, O. S., Alokail, M. S., Al-Othman, A., et al. (2012). Modest reversal of metabolic syndrome manifestations with vitamin D status correction: a 12-month prospective study. Metabolism, 61(5), 661-666.

18. Rostand, S. G., McClure, L. A., Kent, S. T., Judd, S. E., \& Gutierrez, O. M. (2016). Associations of blood pressure, sunlight, and vitamin $\mathrm{D}$ in community-dwelling adults. Journal of Hypertension, 34(9), 1704-1710.

19. Cabrera, S. E., Mindell, J. S., Toledo, M., Alvo, M., \& Ferro, C. J. (2016). Associations of blood pressure with geographical latitude, solar radiation, and ambient temperature: Results from the Chilean health survey, 2009-2010. American Journal of Epidemiology, 183(11), 1071-1073.

20. Kent, S. T., McClure, L. A., Judd, S. E., Howard, V. J., Crosson, W. L., Al-Hamdan, M. Z., et al. (2013). Short- and long-term sunlight radiation and stroke incidence. Annals of Neurology, 73(1), 32-37.

21. Weller, R. B., Wang, Y., He, J., Maddux, F. W., Usvyat, L., Zhang, H., et al. (2020). Does incident solar ultraviolet radiation lower blood pressure? Journal of the American Heart Association, 9(5), e013837.

22. Oplander, C., Volkmar, C. M., Paunel-Gorgulu, A., van Faassen, E. E., Heiss, C., Kelm, M., et al. (2009). Whole body UVA irradiation lowers systemic blood pressure by release of nitric oxide from intracutaneous photolabile nitric oxide derivates. Circulation Research, 105(10), 1031-1040.

23. Muggeridge, D. J., Sculthorpe, N., Grace, F. M., Willis, G., Thornhill, L., Weller, R. B., et al. (2015). Acute whole body UVA irradiation combined with nitrate ingestion enhances time trial performance in trained cyclists. Nitric Oxide, 48, 3-9.

24. Krause, R., Buhring, M., Hopfenmuller, W., Holick, M. F., \& Sharma, A. M. (1998). Ultraviolet B and blood pressure. Lancet, 352(9129), 709-710.

25. Scragg, R., Wishart, J., Stewart, A., Ofanoa, M., Kerse, N., Dyall, L., \& Lawes, C. M. (2011). No effect of ultraviolet radiation on blood pressure and other cardiovascular risk factors. Journal of Hypertension, 29(9), 1749-1756.

26. Hamilton, S. L., Clemes, S. A., \& Griffiths, P. L. (2008). UK adults exhibit higher step counts in summer compared to winter months. Annals of Human Biology, 35(2), 154-169.

27. Graudal, N. A., Hubeck-Graudal, T., \& Jurgens, G. (2017). Effects of low sodium diet versus high sodium diet on blood pressure, renin, aldosterone, catecholamines, cholesterol, and triglyceride. Cochrane Database of Systematic Reviews, 4, CD004022.

28. Murray, C. J., Ezzati, M., Flaxman, A. D., Lim, S., Lozano, R., Michaud, C., et al. (2012). GBD 2010: design, definitions, and metrics. Lancet, 380(9859), 2063-2066. 
29. Murray, C. J., Ortblad, K. F., Guinovart, C., Lim, S. S., Wolock, T. M., Roberts, D. A., et al. (2014). Global, regional, and national incidence and mortality for HIV, tuberculosis, and malaria during 1990-2013: A systematic analysis for the Global Burden of Disease Study 2013. Lancet, 384(9947), 1005-1070.

30. Lindqvist, P., Epstein, E., \& Olsson, H. (2009). Does an active sun exposure habit lower the risk of venous thrombotic events? A D-lightful hypothesis. $J T H, 7,605-610$.

31. Holick, M. F. (2016). Biological effects of sunlight, ultraviolet radiation, visible light, infrared radiation and vitamin $\mathrm{D}$ for health. Anticancer Research, 36(3), 1345-1356.

32. Brotman, D. J., Golden, S. H., \& Wittstein, I. S. (2007). The cardiovascular toll of stress. Lancet, 370(9592), 1089-1100.

33. Bruno, R. M., Ghiadoni, L., Seravalle, G., Dell'oro, R., Taddei, S., \& Grassi, G. (2012). Sympathetic regulation of vascular function in health and disease. Frontiers in Physiology, 3, 284.

34. Spruill, T. M., Butler, M. J., Thomas, S. J., Tajeu, G. S., Kalinowski, J., Castaneda, S. F., et al. (2019). Association between high perceived stress over time and incident hypertension in black adults: Findings from the Jackson heart study. Journal of the American Heart Association, 8(21), e012139.

35. Thomas, J., \& Al-Anouti, F. (2018). Sun exposure and behavioral activation for hypovitaminosis D and depression: A controlled pilot study. Community Mental Health Journal, 54(6), 860-865.

36. Edstrom, D. W., Linder, J., Wennersten, G., Brismar, K., \& Ros, A. M. (2010). Phototherapy with ultraviolet radiation: A study of hormone parameters and psychological effects. Journal of the European Academy of Dermatology and Venereology, 24(4), 403-409.

37. Zhang, B., Ma, S., Rachmin, I., He, M., Baral, P., Choi, S., et al. (2020). Hyperactivation of sympathetic nerves drives depletion of melanocyte stem cells. Nature, 577(7792), 676-681.

38. Thomas. S.J., Booth, J.N., 3rd, Dai, C., Li, X., Allen, N., Calhoun, D., Carson, A.P., Gidding, S., Lewis, C.E., Shikany, J.M., Shimbo, D., Sidney, S., Muntner, P. (2018). Cumulative incidence of hypertension by 55 years of age in blacks and whites: The CARDIA study. Journal of the American Heart Association, 7(14), 1-10.
39. Lindqvist, P. G., Epstein, E., Landin-Olsson, M., Akerlund, M., \& Olsson, H. (2020). Women with fair phenotypes seem to confer a survival advantage in a low UV milieu. A nested matched case control study. PLoS ONE, 15(1), e0228582.

40. Sun, Z., Cade, R., \& Morales, C. (2002). Role of central angiotensin II receptors in cold-induced hypertension. American Journal of Hypertension, 15(1 Pt 1), 85-92.

41. Onozuka, D., \& Hagihara, A. (2017). Solar radiation and out-ofhospital cardiac arrest in Japan. Environmental Pollution, 230, 46-52.

42. Khan, F. A., Engstrom, G., Jerntorp, I., Pessah-Rasmussen, H., \& Janzon, L. (2005). Seasonal patterns of incidence and case fatality of stroke in Malmo, Sweden: The STROMA study. Neuroepidemiology, 24(1-2), 26-31.

43. Bruno, R. M., \& Taddei, S. (2015). " "tis bitter cold and I am sick at heart": Establishing the relationship between outdoor temperature, blood pressure, and cardiovascular mortality. European Heart Journal, 36(19), 1152-1154.

44. Yang, L., Li, L., Lewington, S., Guo, Y., Sherliker, P., Bian, Z., et al. (2015). Outdoor temperature, blood pressure, and cardiovascular disease mortality among 23,000 individuals with diagnosed cardiovascular diseases from China. European Heart Journal, 36(19), 1178-1185.

45. Rylander, A., \& Lindqvist, P. G. (2011). Eclampsia is more prevalent during the winter season in Sweden. Acta Obstetricia et Gynecologica Scandinavica, 90(1), 114-117.

46. Thieden, E., Jorgensen, H. L., Jorgensen, N. R., Philipsen, P. A., \& Wulf, H. C. (2008). Sunbed radiation provokes cutaneous vitamin D synthesis in humans-a randomized controlled trial. Photochemistry and Photobiology, 84(6), 1487-1492.

47. Duffy, S. W., Rohan, T. E., \& McLaughlin, J. R. (1994). Design and analysis considerations in a cohort study involving repeated measurement of both exposure and outcome: The association between genital papillomavirus infection and risk of cervical intraepithelial neoplasia. Statistics in Medicine, 13(4), 379-390. 